\title{
Physico-chemical and Biological Evaluation of Flavonols: Fisetin, Quercetin and Kaempferol Alone and Incorporated in beta Cyclodextrins
}

\author{
Danciu Corina $^{\mathrm{a},{ }^{*}}$, Florina Bojin ${ }^{\mathrm{b}}$, Rita Ambrus ${ }^{\mathrm{c}}$, Delia Muntean ${ }^{\mathrm{d}}$, Codruta Soica $^{\mathrm{e}}$, Virgil Paunescu ${ }^{\mathrm{b}}$, \\ Mirabela Cristea $^{b}$, Iulia Pinzaru ${ }^{f}$ and Cristina Dehelean ${ }^{f}$
}

\begin{abstract}
${ }^{a}$ Department of Pharmacognosy, University of Medicine and Pharmacy "Victor Babeş", Eftimie Murgu Square, No. 2, 300041 Timişoara, România; ${ }^{b}$ Department of Functional Sciences, University of Medicine and Pharmacy "Victor Babeş", Eftimie Murgu Square, No. 2, 300041 Timişoara, România; ${ }^{c}$ Department of Pharmaceutical Technology, University of Szeged, Dóm tér 8., Szeged H6720, Hungary; 'Department of Microbiology-Virology, University of Medicine and Pharmacy "Victor Babeş", Eftimie Murgu Square, No. 2, 300041 Timişoara, România; ${ }^{e}$ Department of Pharmaceutical Chemistry, University of Medicine and Pharmacy "Victor Babeş", Eftimie Murgu Square, No. 2, 300041 Timişoara, România, ${ }^{f}$ Department of Toxicology, University of Medicine and Pharmacy "Victor Babeş", Eftimie Murgu Square, No. 2, 300041 Timişoara, România
\end{abstract}

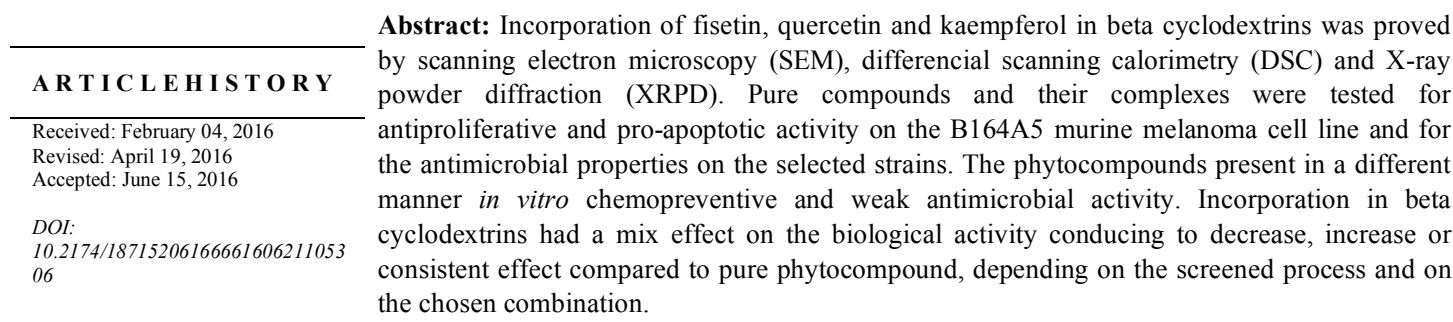

Keywords: Fisetin, quercetin, kaempferol, beta- cyclodextrins, chemopreventive, antimicrobial.

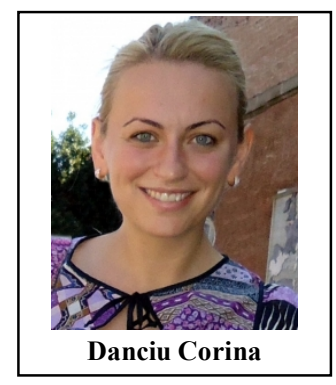

\section{INTRODUCTION}

Natural compounds and their chemical derivatives have represented among years invaluable sources of both consecrated and new therapeutic agents [1]. Accordingly to a recent report of WHO (World Health Organization) over 80\% of world's populations is using total plant extracts or isolated phytocompounds for their primary health care needs (www.who.int). Flavonoids represent one of the most studied classes of phytocompounds. Studies in the field show their role in the prevention of degenerative diseases including cancers, cardiovascular and neurodegenerative diseases [2]. From the chemical point of view flavonoids comprise a large group of polyphenolic compounds having in common a benzo- $\gamma$-pyrone structure [3]. Flavonols are an important subclass of flavonoids that have a 3-hydroxyflavone backbone [4]. They can be found in an increased number of vegetables and fruits. Statistics have shown that in western population the range value for the intake of flavonols varies between 2-50 mg per day [5, 6]. Fisetin, quercetin and kaempferol are among the prominent representatives of this class.

Fisetin can be found in strawberries, apples, persimmons, mangoes, kiwi, peach, lotus root, onions, cucumbers and other fruits and vegetables [7]. It was reported to prevent Alzheimer's disease in case of transgenic mice [8]. The flavonol was also depicted for its anti-oxidant, anti-cancer, anti-angiogenic, antiinflammatory, anti-diabetic neuroprotective and neurotrophic effects [9-11]. It supports ERK-dependent long-term potentiation

*Address correspondence to this author at the Department of Pharmacognosy, University of Medicine and Pharmacy "Victor Babeş", Eftimie Murgu Square, No. 2, 300041 Timişoara, România; Tel: 0040744648855;

E-mail: corina.danciu@umft.ro and enhances memory [12]. Fisetin showed also chemopreventive properties against human colon cancer cells HCT116 [13]. Addition of fisetin to cisplatin proved to be a good therapeutic strategy for the elimination of embryonal carcinoma cells [14].

Quercetin can be found in apples, grapes, red wine, blue and black berries, red cherries, citrus, green leafy vegetables, onions, cocoa, tea [15]. It was described as an antioxidant, antiproliverative and antiangiogenic agent [16, 17]. Quercetin supports cardiovascular health, blocks human platelet aggregation and eicosanoid synthesis [18]. It decrease blood pressure in animal models and humans [19]. It has been depicted as an anti-inflammatory agent by inhibiting STAT-1 and NF- $\mathrm{BB}$ activations [20]. Quercetin was found to block the release of substances involved in allergies and to inhibit mast cell secretion [21]. It was also reported as a chemopreventive agent on a wide number of cancers with very good results on prostate and colon cancers [22-24].

Kaempferol can be found in apples, grapes, blackberries, peaches, green tea, tomatoes, potatoes, onions, green leafy vegetables [25]. Epidemiological studies have shown a positive correlation between consummation of nutraceuticals containing kaempferol and a decreased risk of developing several disorders such as cardiovascular diseases and cancer [26]. In vitro and in vivo studies have shown a wide range of biological properties for this flavonol including anti-oxidant, chemo-preventive, cardio-preventive, anti-microbial, anti-angiogenic, neuroprotective, antidiabetic, anti-osteoporotic, anti-allergic properties [26-28]. Kaempferol have proved to have anticancer effects in case of : breast, ovarian, gastric, pancreatic, colorectal, bladder, prostate, lung cancer and leukemia [27, 29].

Solubility may play an important role in the therapeutic efficacy of flavonols. It is well known that in general flavonoids and in this particular discussion fisetin, quercetin and kaempferol have low 
water solubility [3]. This parameter can cause problems in terms of bioavailability of this active agents. Various approaches have been used throughout time in order to modify the dissolution profile of these lipophilic phytocompounds without changing the molecular structure, including: particle size reduction, complexation, use of lipid based system, use of surfactant of delivery in dosage form, incorporation in different types of micro or nano particles, $\mathrm{pH}$ modification, solid dispersion, crystal modification [30]. Cyclodextrins (CD's) have been intensively used in the pharmaceutical field in order to increase the solubility, stability, safety and bioavailability of a wide range of molecules [31, 32]. From the chemical point of view CD's are a family of cyclic oligosaccharides with the ability to form host-guest inclusion complexes with a wide variety of molecules, having a hydrophilic outer surface and a lipophilic central cavity. $\beta$ CD's are naturally occurring CD's and contain 7 glucopyranose units $[31,33]$.

The aim of this study is to proof that the three flavonols can be successfully incorporated in $\beta$ CD's (beta-cyclodextrin (BCD) and hydroxylpropyl-beta-cyclodextrin (HPBCD)) in order to increase their water solubility. A second aim is to evaluate the antimicrobial effect, respectively the antiproliferative and pro apoptotic activity on the B164A5 murine melanoma cell line of pure flavonols and their complexes.

\section{MATERIALS AND METHODS}

\subsection{Reagents}

Fisetin, kaempferol, and quercetin were acquired from Sigma Aldrich (purity $\geq 98 \%$ ). Beta-cyclodextrin (BCD) and hydroxylpropylbeta-cyclodextrin (HPBCD) were acquired from Cyclolab Hungary. All substances were used as received and stored as indicated by the manufacter.

\subsection{Complexes Preparation}

For the preparation of the inclusion complexes the fallowing steps where employed: simple powder mixing, using a mortar and a pestle;kneading with a $50 \%(\mathrm{w} / \mathrm{w})$ water : ethanol solution until the bulk of solvent evaporated and a paste-type product was formed; the mixture was then dried at room temperature for 24 hours and put in the oven, at $105{ }^{\circ} \mathrm{C}$, for several hours until reaching constant weight. The final product was pulverized and sieved. All the binary products were prepared using a molar ratio of 1:2 active substance : CD $($ MwFisetin $=286.23 \mathrm{~g} / \mathrm{mol}$, MwKaempferol $=286.23 \mathrm{~g} / \mathrm{mol}, \mathrm{Mw}$ Quercetin $=302.236 \mathrm{~g} / \mathrm{mol}, \mathrm{MwBCD}=1134.98 \mathrm{~g} / \mathrm{mol}, \mathrm{MwHPBCD}=$ $1396 \mathrm{~g} / \mathrm{mol}$ ). The molar ratio of 1:2 was chosen in order to achieve a better water solubility for active phytocompounds.

\subsection{Scanning Electron Microscopy (SEM)}

The morphology of the particles was examined by SEM (Hitachi S4700, Hitachi Scientific Ltd., Tokyo, Japan). A sputter coating apparatus (Bio-Rad SC 502, VG Microtech, Uckfield, UK) was applied to induce electric conductivity on the surface of the samples. The air pressure was $1.3-13.0 \mathrm{mPa}$.

\subsection{Differencial Scanning Calorimetry (DSC)}

The DSC measurements with a Mettler Toledo DSC $821^{\mathrm{e}}$ thermal analysis system with the $\mathrm{STAR}^{\mathrm{e}}$ thermal analysis program V6.0 (Mettler Inc., Schwerzenbach, Switzerland), approximately 2$5 \mathrm{mg}$ of pure drug or product was examined in the temperature range between $25{ }^{\circ} \mathrm{C}$ and $350{ }^{\circ} \mathrm{C}$. The heating rate was $10{ }^{\circ} \mathrm{C} \mathrm{min}{ }^{-1}$. Argon was used as carrier gas, at a flow rate of $10 \mathrm{l} / \mathrm{h}$ during the DSC investigation.

\subsection{X-ray Powder Diffraction (XRPD)}

XRPD spectra were recorded with a BRUKER D8 Advance Xray diffractometer (Bruker AXS GmbH, Karlsruhe, Germany) system with $\mathrm{Cu} \mathrm{K} \alpha 1$ radiation $(\lambda=1.5406 \AA)$ over the interval 5$30^{\circ} / 2$. The measurement conditions were as follows: target, $\mathrm{Cu}$; filter, $\mathrm{Ni}$; voltage, $40 \mathrm{kV}$; current, $40 \mathrm{~mA}$; time constant, $0.1 \mathrm{~s}$; angular step $0.010^{\circ}$. In the determination of the degree of crystallinity, the total area of the three peaks with largest intensity was examined, after smoothing and background removal

\subsubsection{Cell Culture}

B16 4A5 murine melanoma cell line (Sigma-Aldrich Company, Ayrshire, UK) was cultured in complete growth medium for these cells, containing Dulbecco's Modified Eagle's Medium (DMEM; Gibco BRL, Invitrogen, Carlsbad, CA, USA), supplemented with $10 \%$ fetal calf serum (FCS; PromoCell, Heidelberg, Germany), $1 \%$ Penicillin/Streptomycin mixture (Pen/Strep, 10,000 IU/ml, FCS; PromoCell), and 2\% HEPES (4-(2-hydroxyethyl)-1piperazineethanesulfonic acid; Gibco BRL). The cells were cultured and expanded in standard conditions, at $37{ }^{\circ} \mathrm{C}$ and $5 \% \mathrm{CO}_{2}$ atmosphere. Medium replacement was performed every third day and, upon reaching $80 \%$ to $90 \%$ confluence, the cells were passed using $0.25 \%$ Trypsin-EDTA (ethylenediaminetetraacetic acid) solution (Sigma-Aldrich Company) followed by centrifugation (10 minutes, $300 \mathrm{x} \mathrm{g}$ ) and were replated in T75 culture flasks at a density of 10,000 cells $/ \mathrm{cm}^{2}$ to ensure optimal growth and expansion.

\subsubsection{MTT Assay}

B16 4A5 murine melanoma cell line was seeded onto a 96-well culture plate at a cellular density of 10,000 cells/well and attached to the bottom of the well overnight. After 24 hours, $100 \mu \mathrm{L}$ of new medium containing Dulbecco's Modified Eagle's Medium (DMEM; Gibco BRL, Invitrogen, Carlsbad, CA, USA) and $100 \mu \mathrm{M}$ of the tested substances (dissolved in dimethyl sulfoxide - DMSO; Sigma-Aldrich Company) were added and incubated for $72 \mathrm{~h}$; the medium was supplemented with $10 \%$ fetal calf serum (FCS; PromoCell, Heidelberg, Germany) and 1\% Penicillin/Streptomycin mixture (Pen/Strep, 10,000 IU/ml; PromoCell, Heidelberg, Germany). The melanoma cells were then assayed by the addition of $10 \mu \mathrm{L}$ of $5 \mathrm{mg} / \mathrm{mL}$ MTT solution from the MTT-based in vitro toxicology assay kit (Tox-1; Sigma-Aldrich Company). The intact mitochondrial reductase converted and precipitated MTT as blue crystals during a $4 \mathrm{~h}$ contact period. The precipitated crystals were dissolved in $100 \mu \mathrm{L}$ of lysis solution provided by the manufacturer (Sigma-Aldrich Company). Finally, the reduced MTT was spectrophotometrically analyzed at $570 \mathrm{~nm}$, using a microplate reader (Bio-Rad, Hercules, CA, USA); wells with untreated cells were considered as reference for viability, while DMSO, which was used to prepare stock solutions of the tested substances, was also added on the cells for evaluation of cellular proliferation. All in vitro experiments were carried out on two microplates in quadruplicates for each substance tested and controls.

\subsubsection{Annexin V-PI Assay}

For evaluation of fisetin, quercetin, kaempferol, and their CD complexes effects on B164A5 melanoma cells, these cells were seeded on 6-well culture plates at a cellular density of 10,000 cells $/ \mathrm{cm}^{2}$. The tested substances were added in culture media at a concentration of $100 \mu \mathrm{M}$ and left to interact for 72 hours. Annexin V-FITC (Miltenyi Biotec, Gladbach, Germany) was used in cell death flow cytometric studies (apoptosis) combined with propidium iodide staining solution (BD Biosciences, San Jose, CA, USA) following the manufacturer's protocol. Briefly, $10^{6}$ cells were washed in $1 \times$ Annexin V Binding Buffer (BD Pharmigen), centrifuged at $300 \mathrm{~g}$ for $10 \mathrm{~min}$, resuspended in the same solution and incubated with $10 \mu \mathrm{L}$ of Annexin V-FITC for $15 \mathrm{~min}$ in the dark. After washing the cells with $1 \mathrm{~mL}$ specific binding buffer and centrifugation, the cell pellet was resuspended in $500 \mu \mathrm{L}$ binding buffer, and $1 \mu \mathrm{g} / \mathrm{mL}$ of PI solution was added immediately prior to analysis by flow cytometry. Acquisition of data was performed with 
the Cell Quest Pro software (Becton-Dickinson) on a 2 lasercapable flow cytometer (FACSCalibur; BD Biosciences), and data analyses used Flowing Software 2.5.

\subsubsection{In Vitro Antibacterial Activity}

The selected compounds were screened for their antimicrobial activity against 11 bacterial strains: Bacillus cereus (ATCC 14579), Staphylococcus aureus (ATCC 25923), Streptococcus pyogenes (ATCC 19615), Streptococcus pneumoniae (ATCC 49619) Enterococcus faecalis (ATCC 29212), Escherichia coli (ATCC 25922), Yersinia enterocolitica (ATCC 23715), Klebsiella pneumoniae (ATCC 700603), Proteus mirabilis (ATCC 25933), Pseudomonas aeruginosa (ATCC 27853), Candida albicans (ATCC 10231) by the agar disk-diffusion method.

\subsubsection{Disk Diffusion Method}

The antimicrobial activity of the selected compounds was evaluated according to the guidelines of the National Committee for Clinical Laboratory Standards (NCCLS, 1997) using agar disk diffusion method,Performance Standards for Antimicrobial Disk Susceptibility Tests, Approved standard M2-A6. NCCLS recommends a bacterial suspension with a density equal to a $0.5 \mathrm{McF}$ arland (which gives a final bacterial concentration of 1-2x108 CFU/ml). The Mueller-Hinton agar plates were inoculated with bacterial suspension using a sterile cotton swab. The same method was used also for Candida albicans but in this case the tested suspension was of 2,2 McFarland and the medium was Sabouraud. Solutions of the tested compounds were prepared in DMSO at a concentration of $10 \mathrm{mM}$. Within $15 \mathrm{~min}$ after the plates were inoculated, sterile Whatman no.1 filter paper disks $(6 \mathrm{~mm}$ in diameter) impregnated with the solution in DMSO of the test compounds were distributed evenly on the surface, with at least $30 \mathrm{~mm}$ (center to center) between them. For negative control we used paper disks impregnated with $\mathrm{BCD}$ and HPBCD. Plates inoculated with the bacterial suspensions were incubated at $37^{\circ} \mathrm{C}$ for $24 \mathrm{~h}$. The inhibition zone diameters were measured in millimeters, with a ruler. For all bacterial strains we performed duplicate disk-diffusion tests and average values are reported.

\subsection{Statistics}

The Prism software package (Graph Pad Prism 4.03 for Windows) was used for data presentation. The experiment was repeated three times and results are presented as mean \pm SD. One or two way ANOVA were applied to evaluate statistical significance $(*, \mathrm{p}<0.05 ; * *, \mathrm{p}<0.01 ;$ and $* * *, \mathrm{p}<0.001)$.

\section{RESULTS}

SEM pictures are depicted in Fig. 1; one can notice the crystalline structure of all three natural compounds certified by the presence of defined crystal particles of various shapes and sizes. Also, beta-CD reveals crystalline character as proven by the irregular shaped particles in its composition; HPBCD is of amorphous nature, displaying round, partially broken particles with

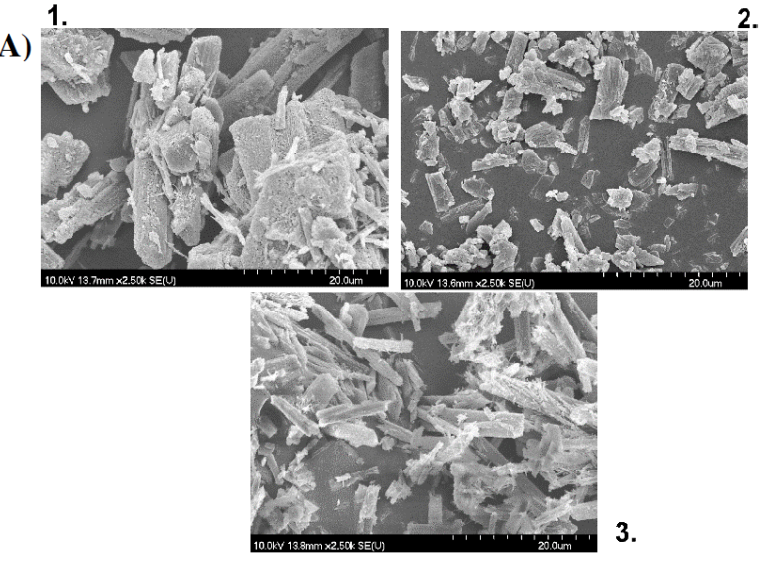

1.

B)

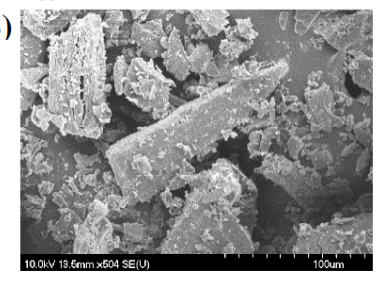

2.

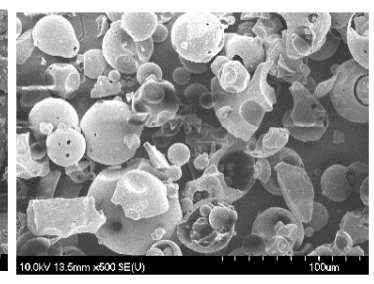

1.

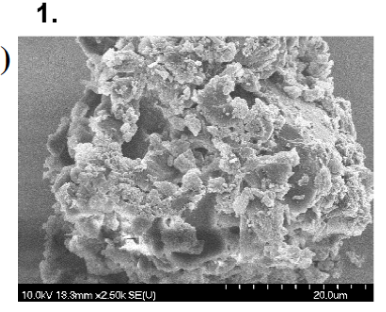

1.

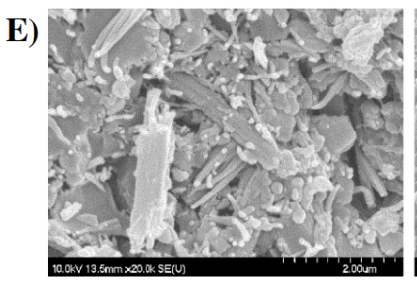

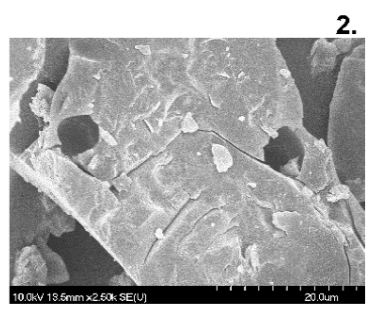

2.

Fig. (1). Scanning electron microscopy (SEM) assay for: A) 1. Fisetin, 2. Kaempferol, 3. Quercetin B) Raw 1. BCD, 2. HPBCD ; C)1. Fisetin:BCD, 2. Fisetin:HPBCD; D) 1. Kaempferol:BCD, 2. Kaempferol:HPBCD; E) 1. Quercetin:BCD, 2. Quercetin:HPBCD 
a clear tendency to aggregate. The beta-CD complexes revealed crystalline structures while the HPBCD based complexes show an amorphous composition of aggregated particles.

The DSC profiles of the natural flavonols, CD and 1:2 complexes are presented in Fig. 2. The two CD's show an endothermic large
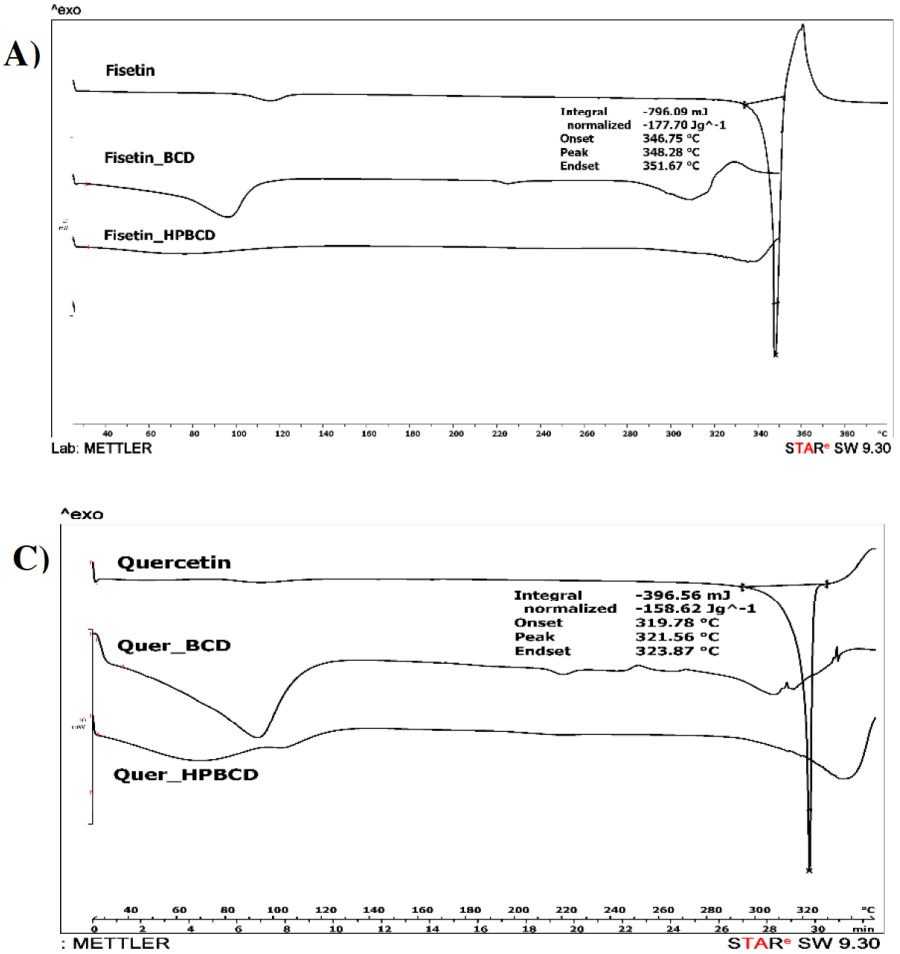

peak below $100^{\circ} \mathrm{C}$, specific for the loss of crystallization water molecules; above $100^{\circ} \mathrm{C}$ the two CD's display a flat profile within the analysis temperature range thus certifying that the melting processes develop above $300^{\circ} \mathrm{C}$. Fisetin (Fig. 2A) shows an endothermic sharp peak at $348^{\circ} \mathrm{C}$ consistent with its melting point; its complexes' DSC profiles display flat curves which certify the
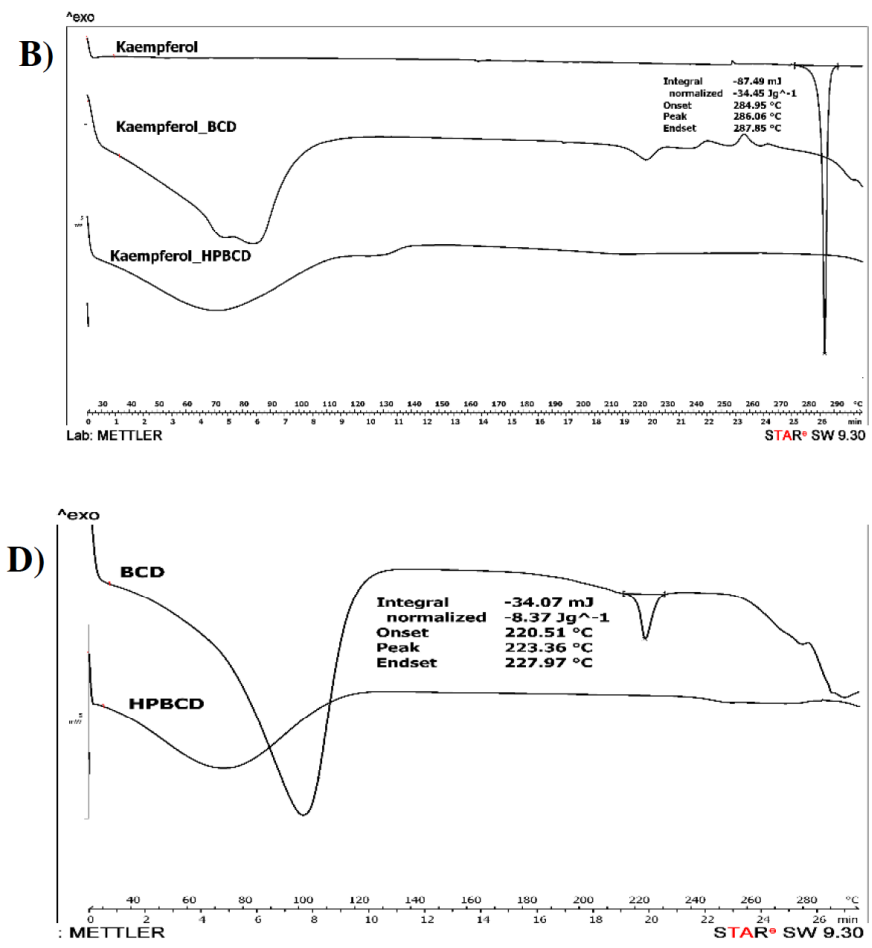

Fig. (2). Differential scanning calorimetry (DSC) for: A) 1. Fisetin and it's CD complexes; B) Kaempferol and it's CD complexes; C) Quercetin and it's CD complexes; D) Raw CD's.
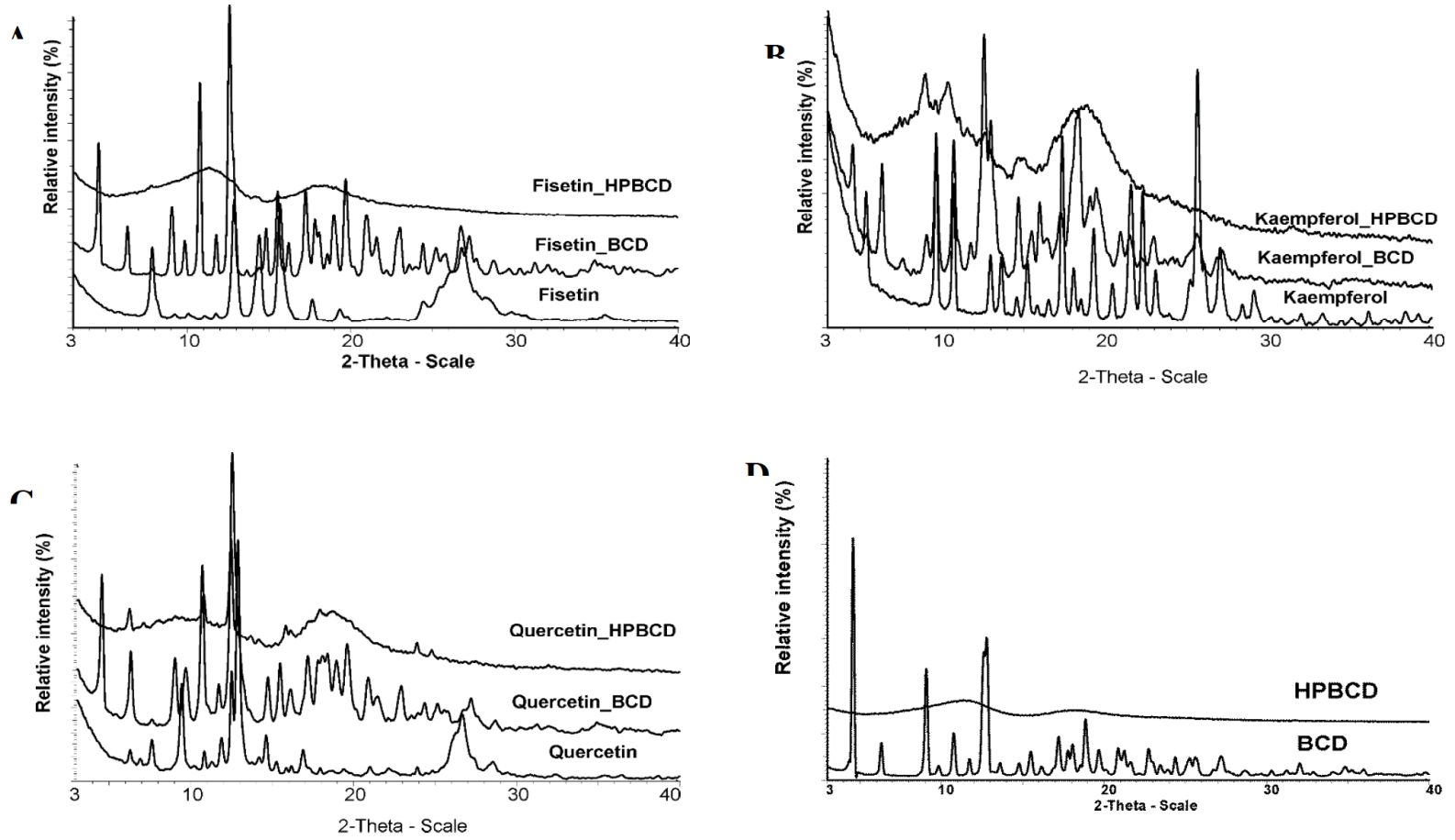

Fig. (3). X-ray diffractograms for for: A) 1. Fisetin and it's CD complexes; B) Kaempferol and it's CD complexes; C) Quercetin and it's CD complexes; D) Raw CD's. 
absence of thermal processes. For kaempferol (Fig. 2B) the melting process is revealed by the endothermic sharp peak at $286^{\circ} \mathrm{C}$ which disappears in the DSC profiles of its CD complexes. Fig. 2C displays the DSC curves for quercetin and its 1;2 complexes; one can notice the sharp endothermic peak at $321^{\circ} \mathrm{C}$ which characterizes the melting point of the pure compound; the DSC profiles of its complexes reveal the absence of thermal processes.

The X-ray diffractograms are showed in Fig. 3; one can notice that all three natural compounds display sharp signals, characteristic for crystalline materials; also, beta-CD has a crystalline structure as proven by the numerous distinct peaks in its diffractogram. HPBCD is an amorphous substance, characterized by almost flat diffractograms. The complexes containing beta-CD as host molecule display distinct sharp peaks, similar to the sum of individual components; however, the appearance of several new peaks as well as the shifting of others can be clearly noticed. The complexes of all three natural compounds with HPBCD are characterized by flat X-ray profiles similar to the corresponding $\mathrm{CD}$.

Table 1. Antimicrobial activity on the selected strains for: A) 1 . Fisetin and it's CD complexes; B) Kaempferol and it's CD complexes; C) Quercetin and it's CD complexes; D) Raw CD's; E) Control.

\begin{tabular}{|c|c|c|c|}
\hline A) & $\mathbf{F}$ & F:BCD & F:HPBCD \\
\hline Escherichia coli & $6 \mathrm{~mm}$ & $6 \mathrm{~mm}$ & $6 \mathrm{~mm}$ \\
\hline Klebsiella pneumoniae & $6 \mathrm{~mm}$ & $6 \mathrm{~mm}$ & $6 \mathrm{~mm}$ \\
\hline Proteus mirabilis & $6 \mathrm{~mm}$ & $6 \mathrm{~mm}$ & $6 \mathrm{~mm}$ \\
\hline Yersinia enterocolitica & $6 \mathrm{~mm}$ & $6 \mathrm{~mm}$ & $6 \mathrm{~mm}$ \\
\hline Pseudomonas aeruginosa & $6 \mathrm{~mm}$ & $6 \mathrm{~mm}$ & $6 \mathrm{~mm}$ \\
\hline Bacillus cereus & $6 \mathrm{~mm}$ & $6 \mathrm{~mm}$ & $6 \mathrm{~mm}$ \\
\hline Streptococcus pneumoniae & $11 \mathrm{~mm}$ & $15 \mathrm{~mm}$ & $10 \mathrm{~mm}$ \\
\hline Streptococcus pyogenes & $15 \mathrm{~mm}$ & $13 \mathrm{~mm}$ & $17 \mathrm{~mm}$ \\
\hline Staphylococcus aureus & $14 \mathrm{~mm}$ & $18 \mathrm{~mm}$ & $18 \mathrm{~mm}$ \\
\hline Enterococcus faecalis & $19 \mathrm{~mm}$ & $15 \mathrm{~mm}$ & $11 \mathrm{~mm}$ \\
\hline Candida albicans & $6 \mathrm{~mm}$ & $6 \mathrm{~mm}$ & $6 \mathrm{~mm}$ \\
\hline B) & $\mathbf{K}$ & K:BCD & K:HPBCD \\
\hline Escherichia coli & $6 \mathrm{~mm}$ & $6 \mathrm{~mm}$ & $6 \mathrm{~mm}$ \\
\hline Klebsiella pneumoniae & $6 \mathrm{~mm}$ & $6 \mathrm{~mm}$ & $6 \mathrm{~mm}$ \\
\hline Proteus mirabilis & $6 \mathrm{~mm}$ & $6 \mathrm{~mm}$ & $6 \mathrm{~mm}$ \\
\hline Yersinia enterocolitica & $6 \mathrm{~mm}$ & $6 \mathrm{~mm}$ & $6 \mathrm{~mm}$ \\
\hline Pseudomonas aeruginosa & $6 \mathrm{~mm}$ & $6 \mathrm{~mm}$ & $6 \mathrm{~mm}$ \\
\hline Bacillus cereus & $12 \mathrm{~mm}$ & $9 \mathrm{~mm}$ & $17 \mathrm{~mm}$ \\
\hline Streptococcus pneumoniae & $11 \mathrm{~mm}$ & $11 \mathrm{~mm}$ & $12 \mathrm{~mm}$ \\
\hline Streptococcus pyogenes & $15 \mathrm{~mm}$ & $15 \mathrm{~mm}$ & $20 \mathrm{~mm}$ \\
\hline Staphylococcus aureus & $15 \mathrm{~mm}$ & $16 \mathrm{~mm}$ & $18 \mathrm{~mm}$ \\
\hline Enterococcus faecalis & $11 \mathrm{~mm}$ & $11 \mathrm{~mm}$ & $11 \mathrm{~mm}$ \\
\hline Candida albicans & $6 \mathrm{~mm}$ & $6 \mathrm{~mm}$ & $6 \mathrm{~mm}$ \\
\hline C) & $\mathbf{Q}$ & Q:BCD & Q:HPBCD \\
\hline Escherichia coli & $6 \mathrm{~mm}$ & $6 \mathrm{~mm}$ & $6 \mathrm{~mm}$ \\
\hline Klebsiella pneumoniae & $6 \mathrm{~mm}$ & $6 \mathrm{~mm}$ & $6 \mathrm{~mm}$ \\
\hline Proteus mirabilis & $6 \mathrm{~mm}$ & $6 \mathrm{~mm}$ & $6 \mathrm{~mm}$ \\
\hline Yersinia enterocolitica & $6 \mathrm{~mm}$ & $6 \mathrm{~mm}$ & $6 \mathrm{~mm}$ \\
\hline Pseudomonas aeruginosa & $6 \mathrm{~mm}$ & $6 \mathrm{~mm}$ & $6 \mathrm{~mm}$ \\
\hline Bacillus cereus & $6 \mathrm{~mm}$ & $6 \mathrm{~mm}$ & $6 \mathrm{~mm}$ \\
\hline Streptococcus pneumoniae & $11 \mathrm{~mm}$ & $11 \mathrm{~mm}$ & $11 \mathrm{~mm}$ \\
\hline
\end{tabular}

\begin{tabular}{|c|c|c|c|}
\hline Streptococcus pyogenes & $15 \mathrm{~mm}$ & $19 \mathrm{~mm}$ & $15 \mathrm{~mm}$ \\
\hline Staphylococcus aureus & $15 \mathrm{~mm}$ & $15 \mathrm{~mm}$ & $15 \mathrm{~mm}$ \\
\hline Enterococcus faecalis & $15 \mathrm{~mm}$ & $13 \mathrm{~mm}$ & $11 \mathrm{~mm}$ \\
\hline Candida albicans & $6 \mathrm{~mm}$ & $6 \mathrm{~mm}$ & $6 \mathrm{~mm}$ \\
\hline D) & \multicolumn{2}{|c|}{ BCD } & HPBCD \\
\hline Escherichia coli & \multicolumn{2}{|c|}{$6 \mathrm{~mm}$} & $6 \mathrm{~mm}$ \\
\hline Klebsiella pneumoniae & \multicolumn{2}{|c|}{$6 \mathrm{~mm}$} & $6 \mathrm{~mm}$ \\
\hline Proteus mirabilis & \multicolumn{2}{|c|}{$6 \mathrm{~mm}$} & $6 \mathrm{~mm}$ \\
\hline Yersinia enterocolitica & \multicolumn{2}{|c|}{$6 \mathrm{~mm}$} & $6 \mathrm{~mm}$ \\
\hline Pseudomonas aeruginosa & \multicolumn{2}{|c|}{$6 \mathrm{~mm}$} & $6 \mathrm{~mm}$ \\
\hline Bacillus cereus & \multicolumn{2}{|c|}{$6 \mathrm{~mm}$} & $6 \mathrm{~mm}$ \\
\hline Streptococcus pneumoniae & \multicolumn{2}{|c|}{$6 \mathrm{~mm}$} & $6 \mathrm{~mm}$ \\
\hline Streptococcus pyogenes & \multicolumn{2}{|c|}{$6 \mathrm{~mm}$} & $6 \mathrm{~mm}$ \\
\hline Staphylococcus aureus & \multicolumn{2}{|c|}{$6 \mathrm{~mm}$} & $6 \mathrm{~mm}$ \\
\hline Enterococcus faecalis & \multicolumn{2}{|c|}{$6 \mathrm{~mm}$} & $6 \mathrm{~mm}$ \\
\hline Candida albicans & \multicolumn{2}{|c|}{$6 \mathrm{~mm}$} & $6 \mathrm{~mm}$ \\
\hline E) & $\begin{array}{c}\text { Gentamicin } \\
\quad 10 \mu \mathrm{g}\end{array}$ & $\begin{array}{c}\text { Gentamicin } \\
120 \mu \mathrm{g}\end{array}$ & $\begin{array}{c}\text { Fluconazol } \\
\quad 25 \mu \mathrm{g}\end{array}$ \\
\hline Escherichia coli & $19 \mathrm{~mm}$ & $6 \mathrm{~mm}$ & $6 \mathrm{~mm}$ \\
\hline Klebsiella pneumoniae & $18 \mathrm{~mm}$ & $6 \mathrm{~mm}$ & $6 \mathrm{~mm}$ \\
\hline Proteus mirabilis & $16 \mathrm{~mm}$ & $6 \mathrm{~mm}$ & $6 \mathrm{~mm}$ \\
\hline Yersinia enterocolitica & $17 \mathrm{~mm}$ & $6 \mathrm{~mm}$ & $6 \mathrm{~mm}$ \\
\hline Pseudomonas aeruginosa & $18 \mathrm{~mm}$ & $6 \mathrm{~mm}$ & $6 \mathrm{~mm}$ \\
\hline Bacillus cereus & $18 \mathrm{~mm}$ & $6 \mathrm{~mm}$ & $6 \mathrm{~mm}$ \\
\hline Streptococcus pneumoniae & $9 \mathrm{~mm}$ & $16 \mathrm{~mm}$ & $6 \mathrm{~mm}$ \\
\hline Streptococcus pyogenes & $9 \mathrm{~mm}$ & $16 \mathrm{~mm}$ & $6 \mathrm{~mm}$ \\
\hline Staphylococcus aureus & $18 \mathrm{~mm}$ & $6 \mathrm{~mm}$ & $6 \mathrm{~mm}$ \\
\hline Enterococcus faecalis & $6 \mathrm{~mm}$ & $19 \mathrm{~mm}$ & $6 \mathrm{~mm}$ \\
\hline Candida albicans & $6 \mathrm{~mm}$ & $6 \mathrm{~mm}$ & $19 \mathrm{~mm}$ \\
\hline
\end{tabular}

Additionaly the study analyzed the antimicrobial potential of the three flavonols: fisetin, quercetin and kaempferol alone and incapsulated in beta-cyclodextrin (BCD) and hydroxylpropyl-betacyclodextrin (HPBCD). The strains include: gram negative bacteria (Escherichia coli, Klebsiella pneumoniae, Proteus mirabilis, Yersinia enterocolitica, Pseudomonas aeruginosa), gram positive bacteria (Bacillus cereus), gram positive cocci (Streptococcus pyogenes, Streptococcus pneumoniae, Staphylococcus aureus, Enterococcus faecalis) and fungus (Candida albicans). Gentamicin $10 \mu \mathrm{g}$ was used as positive control for bacillus and staphylococcus, gentamicin $120 \mu \mathrm{g}$ was used as positive control for streptococci and enterococci and fluconazol $25 \mu \mathrm{g}$ was used as positive control for fungus. For controls diameters were between 16-19 mm. Results are presented in Table 1. A $6 \mathrm{~mm}$ diameter show no antibacterial activity. The selected compounds present a weak antibacterial activity against gram positive cocci. The gram negative bacteria and fungus are resistant at this agents. Slight inhibition could be detected for the gram positive bacteria Bacillus cereus but only in case of kaempferol and it's CD's complexes. For all three active agents, complexation with the three beta CD's increased the antibacterial activity different depending on the bacterial strain. For fisetin in case of $S$. pneumoniae the best activity was recorded after incorporation in $\mathrm{BCD}$, for $S$. pyogenes after incorporation in HPBCD, for $S$. aureus both complexes presented a better antibacterial activity while in case of E. faecalis both complexes decreased the antibacterial activity compared to pure fisetin. For kaempferol in case of $S$. pneumoniae the best activity was recorded after incorporation in $\mathrm{HPBCD}$, for $S$. pyogenes after incorporation 
in HPBCD for $S$. aureus after incorporation in BCD and HPBCD. In case of $E$. faecalis the complexes had the same antibacterial activity compared to pure kaempferol. From the tested flavonols only kaempferol and it's CD's complexes presented antibacterial activity against the gram positive bacteria Bacillus cereus, and in this case the best activity was detected after incorporation in HPBCD. For quercetin in case of $S$. pneumoniae and $S$. aureus the complexes had the same antibacterial activity compared to pure compound. For $S$. pyogenes the best activity was recorded after incorporation in BCD while for E. faecalis complexation in all three cases decreased the antibacterial activity compared to pure quercetin. Results are presented in Table $\mathbf{1 .}$
Morphological aspect of reference/control B164A5 cells shows polygonal shape, clustering tendency and intense direct contact between cells. The cells are grouping and make variable size placards. When treated with fisetin, quercetin, kaempferol and their CD's complexes, the cells lose their polygonal shape and become more fusiform, stretching for contact with the neighboring cells. The grouping tendency is reduced, and we can see single cells very often on the microscopic field, more or less, depending on the tested substance. Results are presented in Fig. 4.

The antiproliferative activity of the tested flavonols and their CD's complexes on B164A5 murine melanoma cell line is rather poor. Among the three tested compounds after $72 \mathrm{~h}$ of incubation

A)
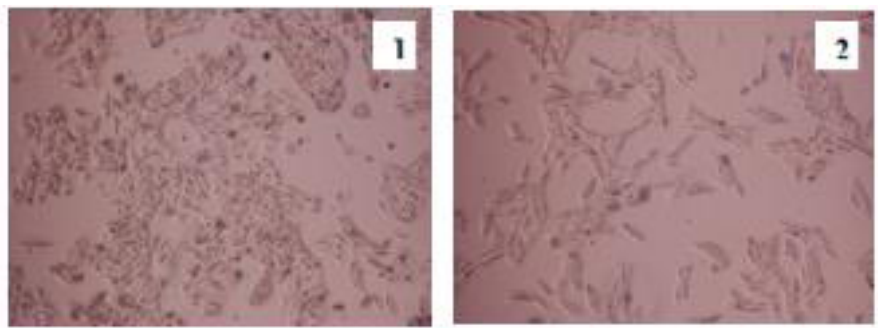

B)
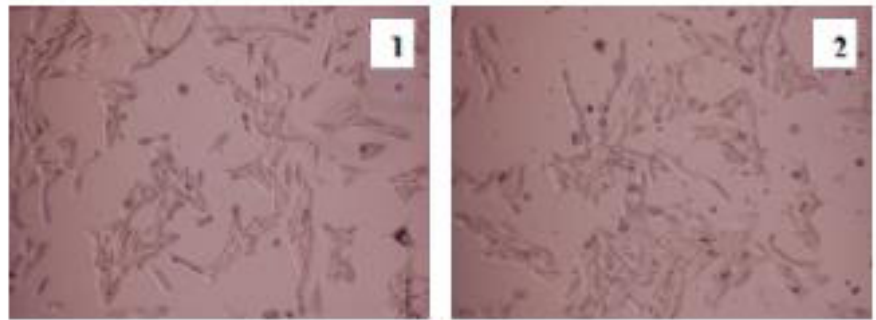

C)
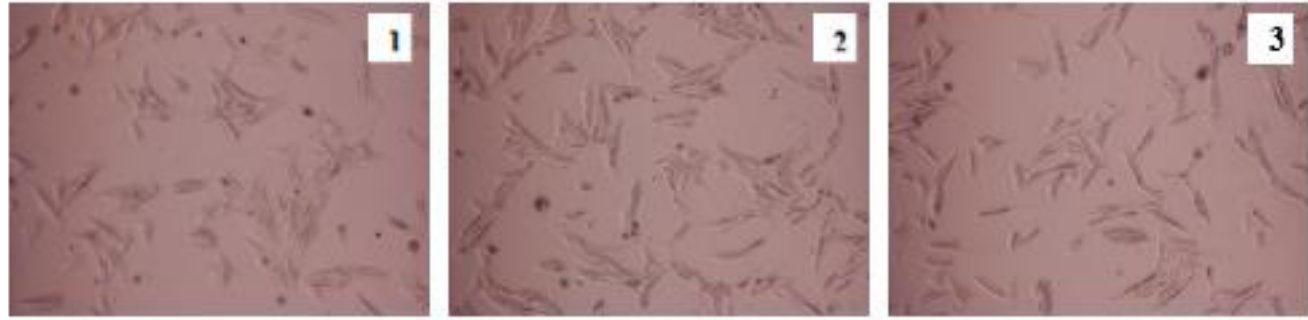

D)
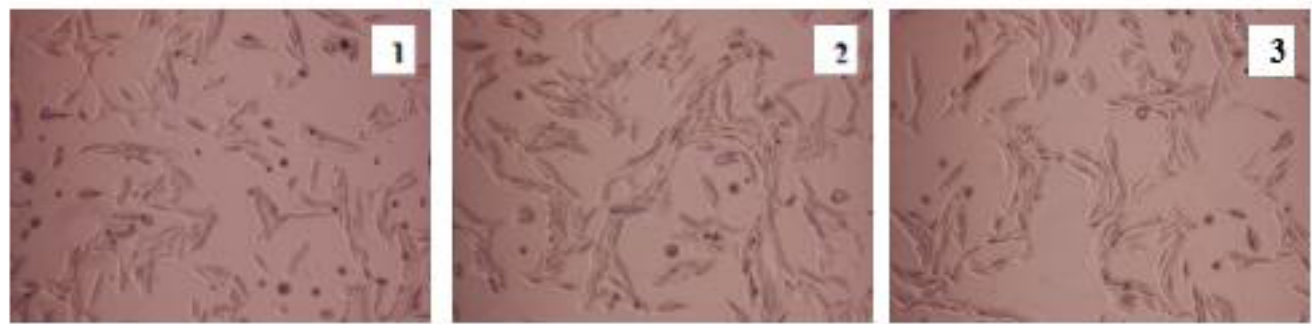

E)
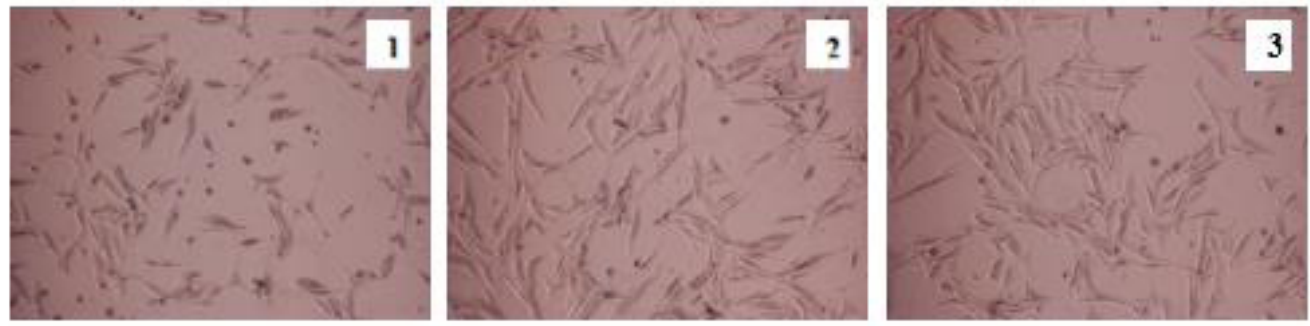

Fig. (4). A) Morphological aspects of control/reference and DMSO-treated cells. 1. Control cells; 2. DMSO-treated cells for 72 hours, Ob. 4x. B) Morphological aspects of cells treated with $\mathrm{CD}$ in vitro for 72 hours. 1. BCD; 2. HPBCD, Ob. 4x. C)Morphological aspects of cells treated with Fisetin and its CD complexes in vitro for 72 hours. 1. Pure substance; 2. BCD complex of Fisetin; 3. HPBCD complex of Fisetin., Ob. 4x. D) Morphological aspects of cells treated with Quercetin and its CD complexes in vitro for 72 hours. 1. Pure substance; 2. BCD complex of Quercetin; 3. HPBCD complex of Quercetin. Ob. 4x. E) Morphological aspects of cells treated with Kaempferol and its CD complexes in vitro for 72 hours. 1. Pure substance; 2. BCD complex of Kaempferol; 3 . HPBCD complex of Kaempferol. Ob. $4 x$ 
B164A5 mouse melanoma cell line

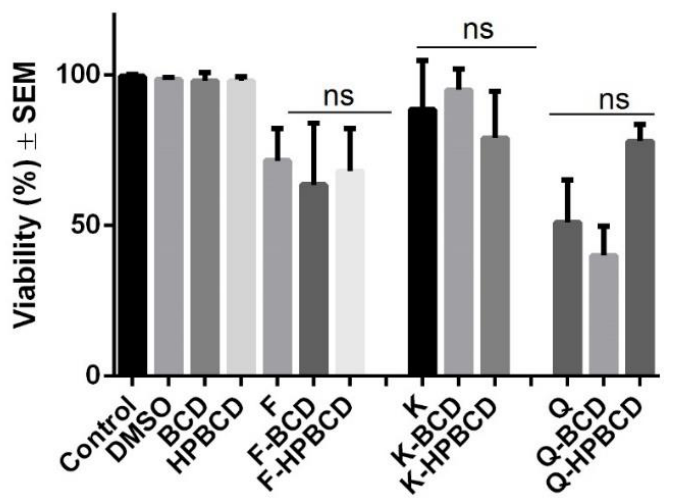

Fig. (5). Viability (\%) of B164A5 mouse melanoma cells after $72 \mathrm{~h}$ of incubation with $100 \mu \mathrm{M}$ of Fisetin (F), Kaempferol (K) and Quercetin (Q) and their cyclodextrin complexes.

and at a concentration of $100 \mu \mathrm{M}$, quercetin showed the strongest antiproliferative activity, the mean value for the viability of cells being $51,2 \pm 14,14$, fallowed by fisetin with $71,5 \pm 10,60$ viable cells and kaempferol with $88,6 \pm 16,26$ viable cells. Encapsulation of this active agents in beta cyclodextrins did not have a significant activity in terms of increasing the antiproliferative activity. For fisetin the viability was sensitive reduced for both $\mathrm{CD}$ complexes. In case of kaempferol the viability was sensitive reduced for the HPBCD complex, while for the BCD complex the viability was slightly increased. Quercetin was the flavonol whose complexs acted really different, namely the $\mathrm{BCD}$ complex decreased the viability and the HPBCD complex significant increased the viability of B164A5 murine melanoma cells. Results can be observed in Fig. 5.

The Annexin-PI double staining show that after a period of incubation of $72 \mathrm{~h}$ at a concentration of $100 \mu \mathrm{M}$ all three flavonols conduced to early and late phenomena of apoptosis. The effects where quite close however, kaempferol was the most active in terms of early apoptotic events with a percentage of $26,55 \pm 8,48$ early apoptotic cells, fallowed by fisetin with a percentage of $21,42 \pm 7,19$ early apoptotic cells and quercetin with a percentage of $18,4 \pm 4,24$ early apoptotic cells. Regarding the late apoptotic events results are quite similar for the three tested compounds, namley : $9,56 \pm 2,83$ late apoptotic cells after incubation with fisetin, $7,15 \pm 3,04$ late apoptotic cells after incubation with kaempferol and $5,54 \pm 4,87$ late apoptotic cells after incubation with quercetin. Incorporation in beta cyclodextrins did not increased the number of early or late apoptotic cells for any of the three complexes. Representative plots of Annexin V-PI staining can be observed in Fig. 6 while mean of the three experiments can be observed in Fig. 7.

\section{DISCUSSIONS}

The physico-chemical analysis use to demonstrate that incorporation took place, are very known "tools" in the pharmaceutical and biomedical field [34-36]. Scanning electron microscopy is a very useful technique to characterize the morphology of solid samples; although it cannot provide strict evidence in terms of complex formation the analysis offers reliable information in the assessment of the final products' composition [37]. All three natural principles reveal a crystalline structure characterized by the presence of distinct particles, some of parallelepiped shape and similar size. Beta-CD is also composed of crystalline particles while HPBCD is an amorphous substances, displaying round particles that form bigger aggregates. The kneaded products reveal a significant change of structure; thus, beta-CD complexes are of crystalline nature, most particular when quercetin is involved. However, the aspect of individual particles is clearly different as compared to the pure compounds. The products obtained using HPBCD as host-molecules reveal an amorphous structure, similar to the pure cyclodextrins, thus leading to the conclusion that a solid state interaction took place. The presence of small particles in the final products together with the aggregation tendency is characteristic for single component amorphous samples [38]; therefore, one can assume that the complexation procedure led to the formation of true inclusion complexes.

Thermal analysis such as differential scanning calorimetry is currently involved in cyclodextrin complexes evaluation due to the valuable information it can provide [38]. In this regard, it has been established that following the inclusion process the normal thermal behavior of the guest-molecule changes significantly as a result to its accommodation inside the cyclodextrin's cavity [33]. Analyzing the DSC profiles of the pure compounds and cyclodextrins versus the DSC profiles of the newly prepared complexes, one can notice that in all three cases the sharp peak indicating the melting point of the substance alone disappears as a result on 1:2 complexation; thus, the DSC profiles of the 1:2 products are practically identical to the curves recorded for the pure cyclodextrins. The disappearance of the endothermal processes characteristic for the pure compounds in the DSC profiles of 1:2 products is a reliable evidence of the total inclusion of the phytocompound inside the respective cyclodextrin.

In order to complete the evaluation of the 1:2 products the XRD analysis was perfomed; it usually provides significant information in terms of crystalline changes due to intermolecular interactions [39]. In the X-ray diffractograms of pure fisetin, kaempferol and quercetine, respectively, as well as beta-CD, the presence of sharp distinct peaks characterizes the crystalline nature of the compound. HPBCD revealed an amorphous nature as proven by the almost flat $\mathrm{X}$-ray profiles. The 1:2 product of beta-CD with fisetin, kaempferol and quercetin, respectively, show crystalline characteristics; however one can notice the appearance of new peaks as well as the shifting in position of some existing individual peaks, thus proving the formation of a new crystalline phase. The presence of new peaks, of different position and intensity as compared to the individual compounds can be regarded as evidence of the formation of the inclusion complex.

The 1:2 products with HPBCD, exhibit an almost flat diffractogram, therefore an amorphous structure; this result can be regarded as a proof of complex formation but also of an amorphisation process that took place due to the kneading procedure.

The selected flavonols have been previously reported for their antimicrobial activity. Fisetin at the conc of $8 \mu \mathrm{g} / \mathrm{mL}$ was reported to inhibit the oral pathogen $S$. mutans. However no activity was recorded in case of $P$. gingivalis or $E$. coli [40]. It was depicted also as an antiviral agent against Dengue virus type-2 [41]. A recent study showed that fisetin inhibits L. monocytogenes virulence [42]. It was published that fisetin inhibit arginase, a central enzyme in $L$. amazonensis infection [43]. In vitro antifungal activity against $H$. courbaril was also described [44]. A range of seven kaempferol rhamnosides were reported for their antimicrobial activity against $S$. aureus, $P$. aeruginosa, S. typhi, $C$. albicans, $C$. parapsilosis and $C$. neoformans [45]. Kaempferol was found to inhibit herpes simplex virus, human coronavirus and rotavirus [46]. This flavonol showed synergic activity with clindamycin against Propionibacterium acnes [47]. Previous studies discuss that kaempferol did not inhibit $E$. coli and $S$. epidermidis but demonstrate antimicrobial activity against $S$. aureus [48]. Debating this results, the group of Panizzi et al., showed that kaempferol present no antimicrobial activity against $S$. aureus and E. coli [49]. The group of Hirai et al., screen the antibacterial activity of quercetin against gram-positive and gram-negative bacteria. The flavonol was found to be selective on 
A)

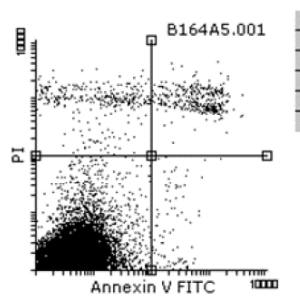

1.

B)

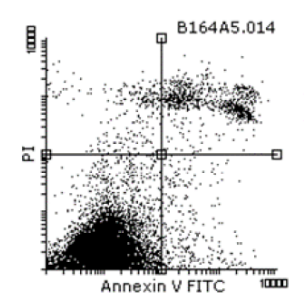

1.

C)

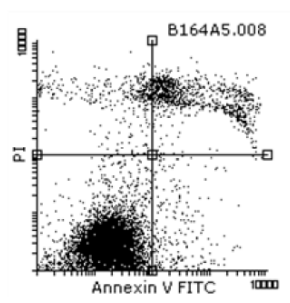

1.

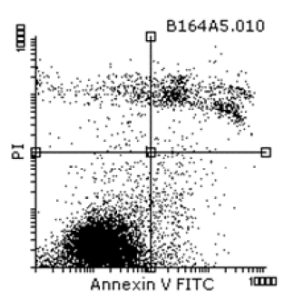

3.

D)

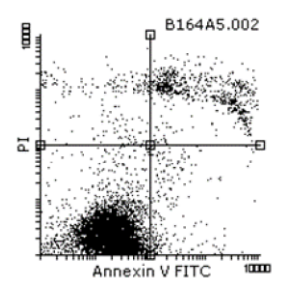

1.

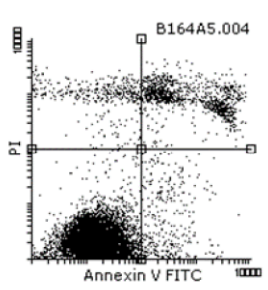

3.

.
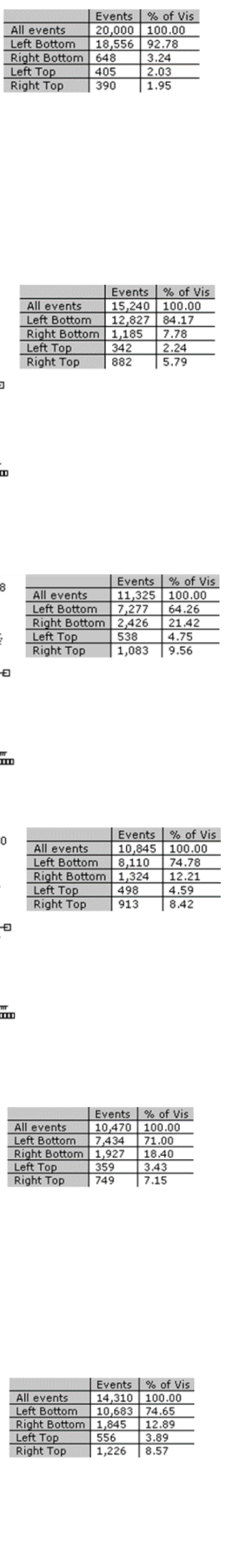
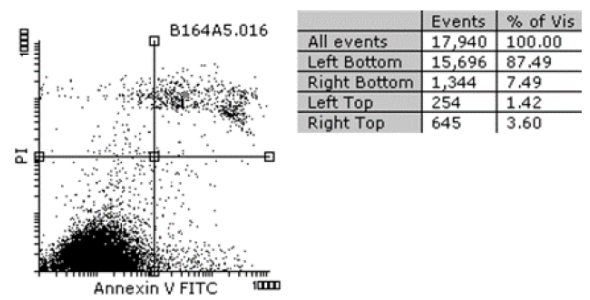

2.
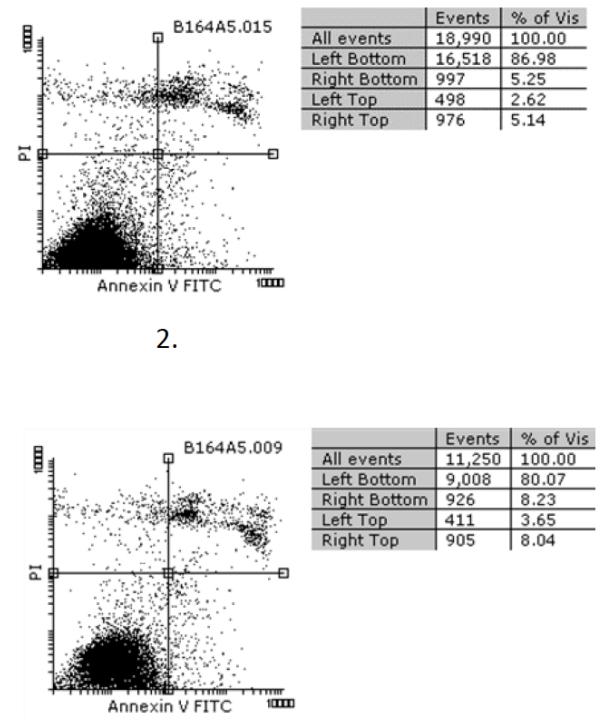

2.
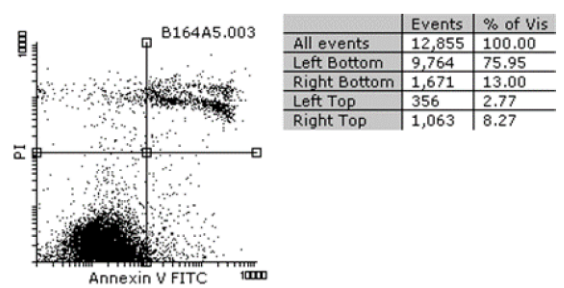

2. 
Fig. (6). contd....

E)

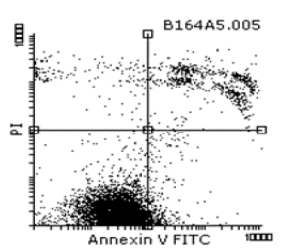

1.

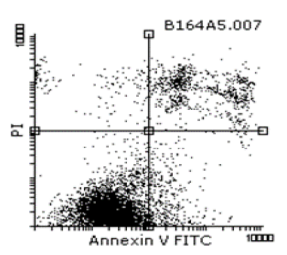

3.
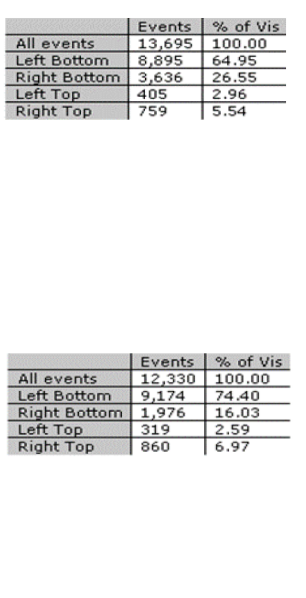

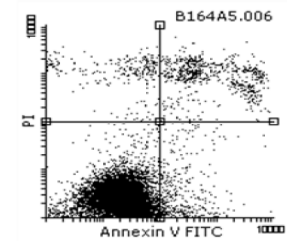

2.

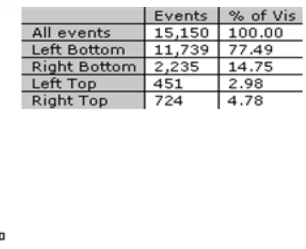

Fig. (6). Representative plots of Annexin V-PI staining. A)1. Control/reference untreated cells; 2. Cells treated with the highest amount of DMSO used for preparing stock solution of the tested substances; B) 1. Cells treated with BCD; 2. Cells treated with HPBCD; C) 1. Fisetin; 2. BCD complex of Fisetin; 3. HPBCD complex of Fisetin; D) 1. Quercetin; 2. BCD complex of Quercetin; 3. HPBCD complex of Quercetin; E). 1. Kaempferol; 2. BCD complex of Kaempferol; 3. HPBCD complex of Kaempferol.

A)

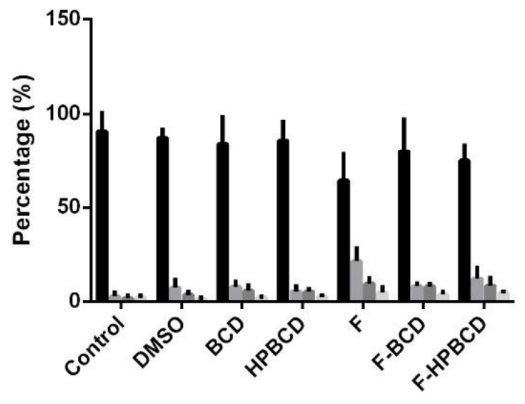

Vital B164A5 cells Early apoptotic B164A5 cells

Late apoptotic B164A5 cells

Necrotic B164A5 cells

B)

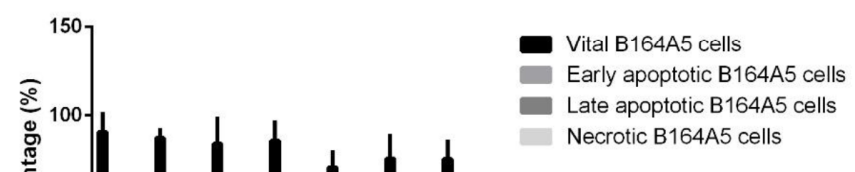

C)

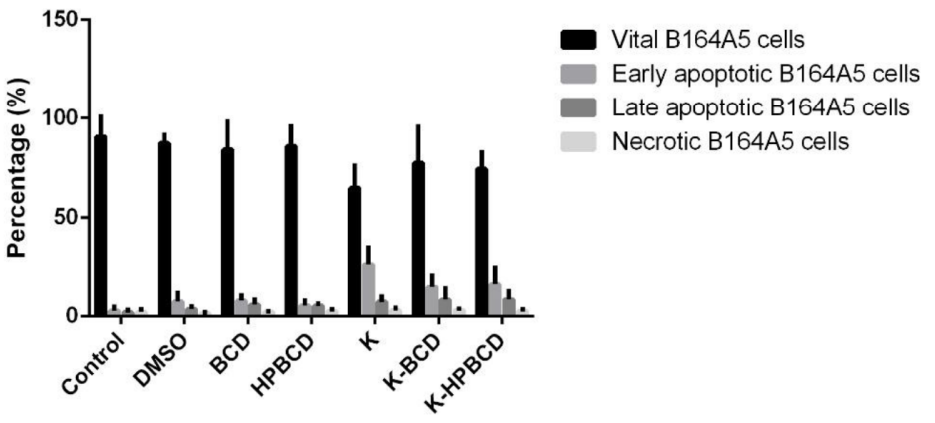

Fig. (7). Mean of the three experiments of Annexin V-PI staining for A) Fisetin and it's CD complexes (Two ways Anova-Interaction-p=0.0404, Row factorp$>0.9999$, Colum factor $\mathrm{p}-<0.0001$ ); B) Quercetin and it's CD complexes (Two ways Anova-Interaction- $\mathrm{p}=0.0926$, Row factor-p $>0.9999$, Colum factor $\mathrm{p}-<$ 0.0001 ); C) Kaempferol and it's CD complexes (Two ways Anova-Interaction-p=0.0232, Row factor-p $>0.9999$, Colum factor-p $<0.0001$ ) 
S. aureus, Methicillin-resistant Staphylococcus aureus (MRSA) and $S$. epidermidis [50]. In addition, new quercetin-derived oxidation products presented antibacterial activity against $H$. pylori and $M R S A$ strains [51]. The phytocompound was evaluated also for it's antimicrobial activity against pathogens of the main oral infectious diseases and was found to be very efficient against $S$. mutans, $S$. sobrinus, $A$. actinomycetemocomitans [52]. The uptake and recognition by specific cellular receptors and transport systems for different types of cyclodextrins have been previously discussed [53]. The group of Lehner et al., showed that for liphophilic compounds complexation with hydroxypropyl-beta-cyclodextrin leads to a stronger antimicrobial activity [54]. Increase antimicrobial activity after incorporation in BCD and HPBCD was reported also for cefdinir [55]. It was published that CD's used as excipients in tooth pastes increase the availability of the antimicrobial agent triclosan [56]. The beneficial effects of complexation with beta-cyclodextrins were brought to light also for six antimycotic imidazole derivatives [57]. In a study of the group of Athanassiou et al. including several beta-lactam antibiotics it was proved that the activity of the cyclodextrin-included beta-lactam antibiotics was increased, particularly against gram-negative strains [53].

As depicted in the results section we can stain that the three flavonols do not have a strong antiproliferative activity against B164A5 murinic melanoma cell line. Among the three compounds quercetin proved to be the best candidate, but the events could be seen at a high dose, namely $100 \mu \mathrm{M}$ and after a long period of incubation, namely $72 \mathrm{~h}$. On the other hand in terms of apoptosis, using the same conditions the effects where quite close for the three flavonols. The explanation could point towards the different mechanism that this natural compounds have for chemoprevention, targeting the mitochondrial dehydrogenase enzyme for antiproliferative activity or the mithocondrial regulation or direct signal transduction for triggering apoptosis. The group of Zhang et al. have shown that quercetin induces apoptosis against B16-BL6 cell line by targeting mitochondria, inhibiting expression of $\mathrm{PKC}$-alpha and translocating PKC-delta [58]. In association with tamoxifen, quercetin was described to sensitize human melanoma cells to hyperthermia [59]. A recent study have shown that the mechanism by which quercetin exerts anti-melanoma effect involves the inhibition of STAT3 signaling [60]. This information was completed by the group of Cao et al., who showed that the phytocompound inhibits $\mathrm{HGF} / \mathrm{c}-\mathrm{Met}$ signaling and HGF-stimulated melanoma cell invasion and migration [61]. In vivo, using the B16-BL6 model it was also proved to inhibit melanoma growth and metastatic potential [62]. Fisetin was reported to be an active agent against human melanoma cells by targeting MAPK and NFKB signaling pathways and by promoting the mesenchymal to epithelial transition [63]. The studies regarding the mechanism of action where completed by the group of Syed et al. who have showed that fisetin acts as an antimelanoma compound through direct binding to p70S6K and mTOR [64]. Kaempferol was described with anti-inflammatory and depigmenting effect [65]. It was shown that it regulates the cyclindependent kinases CDK2 and CDK1 in vitro for human melanoma OCM-1 cell line [66]. It was also showed to inhibit melanogenesis in B164A5 melanoma cell line [67]. Cyclodextrin encapsulation did not have any spectacular effect for none of the three phyto chemicals concerning both proliferation and apoptosis. Research in the field have shown that for some active compounds this kind of modulations can increase the in vitro chemopreventive activity by higher cellular uptake and transfection efficiency [68, 69]. However the discussion can suffer intense debate because some papaers in the field report increased in vitro chemopreventive activity after incorporation in beta-cyclodextrins, others have noticed no change or even decreased chemopreventive activity after this kind of modulation [70-72].

\section{CONCLUSION}

The three flavonols: fisetin, quercetin and kaempferol were successfully incorporated in beta-cyclodextrin (BCD) and hydroxylpropyl-beta-cyclodextrin (HPBCD). The phytocompounds present in a different manner in vitro antiprolifrative and proapoptotic activities on the B164A5 murinic melanoma cell line and weak antimicrobial activity on the selected strains. Incorporation in beta cyclodextrins had a mix effect on the biological activity conducing to decrease, increase or consistent effect compared to pure phytocompound depending on the screened process and on the chosen combination.

\section{CONFLICT OF INTEREST}

Authors declare no conflict of interest. The study was financed by the UMFT grant -Parteneriate în cercetarea fundamentală inovativă-PIII-C2-PCFI-2015/2016acronim FLAVOFORM.

\section{ACKNOWLEDGEMENTS}

DC and CD designed the study and where involved in the article's drafting. RA, DM and IC performed the experiments. FB and $\mathrm{MC}$ analyzed the data. $\mathrm{CS}$ and $\mathrm{VP}$ reviewed the draft for important intellectual content.

\section{LIST OF ABBREVIATIONS}

$\begin{array}{ll}\text { SEM } & =\text { scanning electron microscopy } \\ \text { DSC } & =\text { differencial scanning calorimetry } \\ \text { XRPD } & =\text { X-ray powder diffraction } \\ \text { WHO } & =\text { World Health Organization } \\ \text { BCD } & =\text { beta-cyclodextrin } \\ \text { HPBCD } & =\text { hydroxylpropyl-beta-cyclodextrin } \\ \text { CD's } & =\text { cyclodextrins }\end{array}$

\section{REFERENCES}

[1] Koehn, F.E.; Carter, G.T. The evolving role of natural products in drug discovery. Nat Rev Drug Discov., 2005, 4(3), 206-220.

[2] Tsao, R. Chemistry and Biochemistry of Dietary Polyphenols. Nutrients., 2010, 2(12), 1231-1246.

[3] Kumar, S.; Pandey, A.K. Chemistry and Biological Activities of Flavonoids: An Overview. The Scientific World Journal., 2013, :e162750, doi: 10.1155/2013/162750. eCollection 2013

[4] Dayem, A.A.; Choi, H.Y.; Kim, Y.B.; Cho, S.G. Antiviral Effect of Methylated Flavonol Isorhamnetin against Influenza. PLoS., 2015, doi: 10.1371/journal.pone.0121610

[5] Huxley, R.R.; Neil, H.A.W. The relation between dietary flavonol intake and coronary heart disease mortality: a meta-analysis of prospective cohort studies. Eur J Clin Nutr., 2003, 57(8), 904-908

[6] Cermak, R.; Wolffram, S. The potential of flavonoids to influence drug metabolism and pharmacokinetics by local gastrointestinal mechanisms. Curr Drug Metab, 2006, 7(7), 729-744.

[7] Khan, N.; Syed, D.N.; Ahmad, N.; Mukhtar, H. Fisetin: a dietary antioxidant for health promotion. Antioxid Redox Signal., 2013, 19(2), 151-162.

[8] Currais, A.; Prior, M.; Dargusch, R.; Armando, A.; Ehren, J.; Schubert, D., et al. Modulation of p25 and inflammatory pathways by fisetin maintains cognitive function in Alzheimer's disease transgenic mice. Aging Cell., 2014, 13(2), 379-390.

[9] Sengupta, B.; Banerjee, A.; Sengupta, P.K. Investigations on the binding and antioxidant properties of the plant flavonoid fisetin in model biomembranes. FEBS Letters., 2004, 570(1), 77-81.

[10] Subramanian, P.; Jayakumar, M.; Jayapalan, J.J.; Hashim, O.H. Chronotherapeutic effect of fisetin on expression of urea cycle enzymes and inflammatory markers in hyperammonaemic rats. Pharmacological Reports., 2014, 66(6), 1037-1042. 
[11] Sung, B.; Pandey, M.K.; Aggarwal, B.B. Fisetin, an Inhibitor of Cyclin-Dependent Kinase 6, Down-Regulates Nuclear Factor-kBRegulated Cell Proliferation, Antiapoptotic and Metastatic Gene Products through the Suppression of TAK-1 and ReceptorInteracting Protein-Regulated I $\mathrm{B} \alpha$ Kinase Activation. Mol Pharmacol., 2007, 71(6), 1703-1714.

[12] Maher, P.; Akaishi, T.; Abe, K. Flavonoid fisetin promotes ERKdependent long-term potentiation and enhances memory. Proc Natl Acad Sci U S A, 2006, 103(44), 16568-16573.

[13] Kim J.A.; Lee S.; Kim D.E.; Kim M.; Kwon B.M.; Han D.C. Fisetin, a dietary flavonoid, induces apoptosis of cancer cells by inhibiting HSF1 activity through blocking its binding to the hsp70 promoter. Carcinogenesis., 2015, 36(6), 696-706.

[14] Tripathi, R.; Samadder, T.; Gupta, S.; Surolia, A.; Shaha, C. Anticancer Activity of a Combination of Cisplatin and Fisetin in Embryonal Carcinoma Cells and Xenograft Tumors. Mol Cancer Ther., 2011, 10(2), 255-268.

[15] Alrawaiq, N.S.; Abdullah, A.2014. A review of flavonoid quercetin: metabolism, bioactivity and antioxidant properties. Int. J. of PharmTech Res, 2014, 6(3), 933-941.

[16] Tan, W.; Lin, L.; Li, M.; Zhang, Y.X.; Tong, Y.; Xiao, D., et al. Quercetin, a dietary-derived flavonoid, possesses antiangiogenic potential. Eur J Pharmacol., 2003, 459(2-3), 255-262.

[17] Gulati, N.; Laudet, B.; Zohrabian, V.M.; Murali, R.; JhanwarUniyal, M. The antiproliferative effect of Quercetin in cancer cells is mediated via inhibition of the PI3K-Akt/PKB pathway. Anticancer Res., 2006, 26(2A), 1177-1181.

[18] Pace-Asciak, C.R.; Hahn, S.; Diamandis, E.P.; Soleas, G; Goldberg, D.M. The red wine phenolics trans-resveratrol and quercetin block human platelet aggregation and eicosanoid synthesis: Implications for protection against coronary heart disease. Clinica Chimica Acta., 1995, 235(2), 207-219.

[19] Larson, A.J.; Symons, J.D.; Jalili, T. Therapeutic Potential of Quercetin to Decrease Blood Pressure: Review of Efficacy and Mechanisms. Adv Nutr., 2012, 3(1), 39-46.

[20] Hämäläinen, M.; Nieminen, R.; Vuorela, P.; Heinonen, M.; Moilanen, E. Anti-Inflammatory Effects of Flavonoids: Genistein, Kaempferol, Quercetin, and Daidzein Inhibit STAT-1 and NF-kB Activations, Whereas Flavone, Isorhamnetin, Naringenin, and

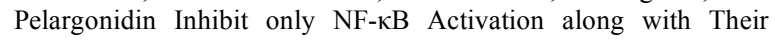
Inhibitory Effect on iNOS Expression and NO Production in Activated Macrophages. Mediators of Inflammation., 2007,; 2007:e45673, doi: 10.1155/2007/45673.

[21] Shaik, Y.B.; Castellani, M.L.; Perrella, A.; Conti, F.; Salini, V.; Tete, S., et al. Role of quercetin (a natural herbal compound) in allergy and inflammation. J Biol Regul Homeost Agents, 2006, 20(3-4), 47-52.

[22] Sharmila, G.; Bhat, F.A.; Arunkumar, R.; Elumalai, P.; Raja Singh, P.; Senthilkumar, K., et al. Chemopreventive effect of quercetin, a natural dietary flavonoid on prostate cancer in in vivo model. Clin Nutr., 2014, 33(4), 718-726.

[23] Shan, B.E.; Wang, M.X.; Li, R.X. Quercetin inhibit human SW480 colon cancer growth in association with inhibition of cyclin D1 and survivin expression through $\mathrm{Wnt} / \mathrm{beta}$-catenin signaling pathway. Cancer Invest., 2009, 7(6), 604-612.

[24] Yang, K.; Lamprecht, S.A.; Liu, Y.; Shinozaki, H.; Fan, K.; Leung, D., et al. Chemoprevention studies of the flavonoids quercetin and rutin in normal and azoxymethane-treated mouse colon. Carcinogenesis, 2000, 21(9), 1655-1660.

[25] Miean, K.H.; Mohamed, S. Flavonoid (myricetin, quercetin, kaempferol, luteolin, and apigenin) content of edible tropical plants. J Agric Food Chem., 2001, 49(6), 3106-3112.

[26] Calderón-Montaño, J.M.; Burgos-Morón, E.; Pérez-Guerrero, C.; López-Lázaro, M. A review on the dietary flavonoid kaempferol. Mini Rev Med Chem., 2011, 11(4), 298-344.

[27] Chen, A.Y.; Chen, Y.C. A review of the dietary flavonoid, kaempferol on human health and cancer chemoprevention. Food Chemistry, 2013, 138(4), 2099-20107.

[28] Lin, J.; Rexrode, K.M.; Hu, F.; Albert, C.M.; Chae, C.U.; Rimm, E.B. et al. Dietary Intakes of Flavonols and Flavones and Coronary Heart Disease in US Women. Am J Epidemiol., 2007, 165(11), 1305-1313.

[29] Sak, K. Cytotoxicity of dietary flavonoids on different human cancer types. Pharmacogn Rev., 2014, 8(16), 122-146.

[30] Balvinder, N.G. Poorly Water Soluble Drugs: Change in Solubility for Improved Dissolution Characteristics a Review. Global Journal of Pharmacology., 2014, 8(1), 26-35.
[31] Rasheed, A. Cyclodextrins as Drug Carrier Molecule: A Review. Scientia Pharmaceutica., 2008, 76(4), 567-598.

[32] Soica, C.; Danciu, C.; Savoiu-Balint, G.; Borcan,.F; Ambrus, R.; Zupko, I., et al. Betulinic acid in complex with a gammacyclodextrin derivative decreases proliferation and in vivo tumor development of non-metastatic and metastatic B164A5 cells. Int J Mol Sci., 2014, 15(5), 8235-8255.

[33] Danciu, C.; Soica, C.; Oltean, M.; Avram, S.; Borcan, F.; Csanyi, E., et al., Genistein in 1:1 inclusion complexes with ramified cyclodextrins: theoretical, physicochemical and biological evaluation. Int J Mol Sci., 2014, 15(2), 1962-1982.

[34] Pomázi, A.; Ambrus R.; Sipos, P.; Szabó-Révész, P. Analysis of co-spray-dried meloxicam-mannitol systems containing crystalline microcomposites. Journal of Pharmaceutical and Biomedical Analysis, 2011, 56(2), 183-190.

[35] Pomázi, A.; Buttini, F.; Ambrus R.; Colombo, P.; Szabó-Révész, P. Effect of polymers for aerolization properties of mannitol-based microcomposites containing meloxicam. European Polymer Journal, 2013, 49(9), 2518-2527.

[36] Danciu, C.; Soica, C.; Csanyi, E.; Ambrus, R.; Feflea, S.; Peev, C.; Dehelean, C. Changes in the anti-inflammatory activity of soy isoflavonoid genistein versus genistein incorporated in two types of cyclodextrin derivatives, 2012, 6(1), 58. doi: 10.1186/1752-153X6-58.

[37] Soica, C.M.; Peev, C.; Ciurlea, S.; Ambrus R.; Dehelean, C. Physico-chemical and toxicological evaluations of betulin and betulinic acid interactions with hydrophilic cyclodextrins. Farmacia, 2010, 58 (5), 611-619.

[38] Şoica, C.; Dehelean, C.; Danciu, C.; Wang, H.M.; Wenz, G; Ambrus, R., et al. Betulin Complex in $\gamma$-Cyclodextrin Derivatives: Properties and Antineoplasic Activities in In Vitro and In Vivo Tumor Models. International Journal of Molecular Sciences., 2012 13(11), 14992-15011.

[39] Dehelean, C.A.; Soica, C.; Peev, C.; Gruia, A.T.; Secleman, E. Physico-chemical and molecular analysis of antitumoral pentacyclic triterpenes in complexation with gamma-cyclodextrin, Revista de Chimie, 2008, 59(8), 887-890.

[40] Patra, J.K.; Kim, E.S. Oh, K.; Kim, H.J.; Dhakal, R.; Kim, Y., et al. Bactericidal effect of extracts and metabolites of Robinia pseudoacacia L. on Streptococcus mutans and Porphyromonas gingivalis causing dental plaque and periodontal inflammatory diseases. Molecules., 2015, 20(4), 6128-6139.

[41] Keivan, Z.; Boon-Teong, T.; Sing-Sin, S.; Pooi-Fong, W.; Mohd, R.M.; Sazaly, A. In vitro antiviral activity of fisetin, rutin and naringenin against dengue virus type-2. Journal of Medicinal Plants Research., 2014, 8(6), 307-12.

[42] Wang, J.; Qiu, J.; Tan, W.; Zhang, Y.; Wang, H.; Zhou, X., et al. Fisetin inhibits Listeria monocytogenes virulence by interfering with the oligomerization of listeriolysin O. J Infect Dis., 2015, 211(9), 1376-1387.

[43] Manjolin, L.C.; Reis, M.B.G.; Maquiaveli, C. do C.; Santos-Filho, O.A.; da Silva ER. Dietary flavonoids fisetin, luteolin and their derived compounds inhibit arginase, a central enzyme in Leishmania (Leishmania) amazonensis infection. Food Chemistry, 2013, 141(3), 2253-2262.

[44] Da Costa, M.P.; Bozinis, M.C.V.; Andrade, W.M.; Costa, C.R.; da Silva, A.L.; Oliveira, C.M.A., et al. Antifungal and cytotoxicity activities of the fresh xylem sap of Hymenaea courbaril L. and its major constituent fisetin. BMC Complementary and Alternative Medicine., 2014, 14(1), 245, doi:10.1186/1472-6882-14-245.

[45] Tatsimo, S.J.; Tamokou, J.D.; Havyarimana, L.; Csupor, D.; Forgo, P.; Hohmann, J, et al. Antimicrobial and antioxidant activity of kaempferol rhamnoside derivatives from Bryophyllum pinnatum. BMC Research Notes, 2012, 5(1), 158, doi:10.1186/1756-0500-5158

[46] Cushnie, T.P.T.; Lamb, A.J. Antimicrobial activity of flavonoids. Int J Antimicrob Agents., 2005, 26(5), 343-356.

[47] Lim, Y.H.; Kim, I.H.; Seo, J.J. In vitro activity of kaempferol isolated from the Impatiens balsamina alone and in combination with erythromycin or clindamycin against Propionibacterium acnes. J Microbiol., 2007, 45(5), 473-477.

[48] Rauha, J.P.; Remes, S.; Heinonen, M.; Hopia, A.; Kähkönen, M.; Kujala, T., et al. Antimicrobial effects of Finnish plant extracts containing flavonoids and other phenolic compounds. Int J Food Microbiol., 2000, 56(1), 3-12. 
[49] Panizzi, L.; Caponi, C.; Catalano, S.; Cioni, P.L.; Morelli, I. In vitro antimicrobial activity of extracts and isolated constituents of Rubus ulmifolius. J Ethnopharmacol., 2002, 79(2), 16516-16518.

[50] Hirai, I.; Okuno, M.; Katsuma, R.; Arita, N.; Tachibana, M.; Yamamoto, Y. Characterisation of anti-Staphylococcus aureus activity of quercetin. International Journal of Food Science \& Technology, 2010, 45(6), 1250-1254.

[51] Ramos, F.A.; Takaishi, Y.; Shirotori, M.; Kawaguchi, Y.; Tsuchiya, K.; Shibata, H., et al. Antibacterial and Antioxidant Activities of Quercetin Oxidation Products from Yellow Onion (Allium cepa) Skin. J Agric Food Chem., 2006, 54(10), 3551-3557.

[52] Shu, Y.; Liu, Y.; Li, L.; Feng, J.; Lou, B.; Zhou, X., et al. Antibacterial activity of quercetin on oral infectious pathogens. African Journal of Microbiology Research, 2011, 5(30), 5358-5361.

[53] Athanassiou, G.; Michaleas, S.; Lada-Chitiroglou, E.; Tsitsa, T.; Antoniadou-Vyza, E. Antimicrobial activity of beta-lactam antibiotics against clinical pathogens after molecular inclusion in several cyclodextrins. A novel approach to bacterial resistance. J Pharm Pharmacol., 2003, 55(3), 291-300.

[54] Lehner, S.J.; Müller, B.W.; Seydel, J.K. Effect of hydroxypropylbeta-cyclodextrin on the antimicrobial action of preservatives. $\mathrm{J}$ Pharm Pharmacol., 1995, 46(3), 186-191

[55] Aleem, O.; Kuchekar, B; Pore, Y.; Late, S. Effect of betacyclodextrin and hydroxypropyl beta-cyclodextrin complexation on physicochemical properties and antimicrobial activity of cefdinir. J Pharm Biomed Anal, 2008, 47(3), 535-540.

[56] Del Valle, E.M.M. Cyclodextrins and their uses: a review. Process Biochemistry., 2004, 39(9), 1033-1046.

[57] Doorne, H.V.; Bosch, E.H., Lerk, C.F. Formation arid antimicrobial activity of complexes of $\beta$-cyclodextrin and some antimycotic imidazole derivatives. Pharmaceutisch Weekblad Scientific Edition., 1988, 10(2), 80-85.

[58] Zhang, X.M.; Chen, J.; Xia, Y.G.; Xu, Q. Apoptosis of murine melanoma B16-BL6 cells induced by quercetin targeting mitochondria, inhibiting expression of PKC-alpha and translocating PKC-delta. Cancer Chemother Pharmacol., 2005, 55(3), 251-262.

[59] Piantelli, M.; Tatone, D.; Castrilli, G.; Savini, F.; Maggiano, N.; Larocca, L.M., et al. Quercetin and tamoxifen sensitize human melanoma cells to hyperthermia. Melanoma Res., 2001, 11(5), 469476.

[60] Cao, H.H.; Tse, A.K.W.; Kwan, H.Y.; Yu, H.; Cheng, C.Y.; Su, T., et al. Quercetin exerts anti-melanoma activities and inhibits STAT3 signaling. Biochem Pharmacol., 2014, 87(3), 424-434.

[61] Cao, H.H.; Cheng, C.Y.; Su, T.; Fu, X.Q.; Guo, H.; Li, T. et al. Quercetin inhibits $\mathrm{HGF} / \mathrm{c}-\mathrm{Met}$ signaling and HGF-stimulated melanoma cell migration and invasion. Mol Cancer, 2015, 14:103, DOI: 10.1186/s12943-015-0367-4.

[62] Caltagirone, S.; Rossi, C.; Poggi, A.; Ranelletti, F.O.; Natali, P.G.; Brunetti, M. et al. Flavonoids apigenin and quercetin inhibit melanoma growth and metastatic potential. Int J Cancer., 2000, 87(4), 595-600.

[63] Pal, H.C.; Sharma, S.; Strickland, L.R.; Katiyar, S.K.; Ballestas, M.E.; Athar, M., et al. Fisetin inhibits human melanoma cell invasion through promotion of mesenchymal to epithelial transition and by targeting MAPK and NFKB signaling pathways. PLoS ONE., 2014, 9(1), e86338, doi: 10.1371/journal.pone.0086338. eCollection 2014

[64] Syed, D.N.; Chamcheu, J.C; Khan, M.I.; Sechi M.; Lall, R.K.; Adhami, VM., et al. Fisetin inhibits human melanoma cell growth through direct binding to p70S6K and mTOR: Findings from 3-D melanoma skin equivalents and computational modeling. Biochemical Pharmacology, 2014, 89(3), 349-360.

[65] Rho, H.S.; Ghimeray, A.K.; Yoo, D.S.; Ahn, S.M.; Kwon, S.S.; Lee, K.H., et al. Kaempferol and kaempferol rhamnosides with depigmenting and anti-inflammatory properties. Molecules., 2011, 16(4), 3338-3344.

[66] Casagrande, F.; Darbon, J.M. Effects of structurally related flavonoids on cell cycle progression of human melanoma cells: regulation of cyclin-dependent kinases CDK2 and CDK11. Biochemical Pharmacology, 2001, 61(10), 1205-1215.

[67] Matsuda, H.; Nakashima, S.; Oda, Y.; Nakamura, S.; Yoshikawa, M. Melanogenesis inhibitors from the rhizomes of Alpinia officinarum in B16 melanoma cells. Bioorganic \& Medicinal Chemistry, 2009, 17(16), 6048-6053.

[68] Yadav, V.R.; Prasad, S.; Kannappan, R.; Ravindran, J.; Chaturvedi, M.M.; Vaahtera, L., et al. Cyclodextrin-complexed curcumin exhibits anti-inflammatory and antiproliferative activities superior to those of curcumin through higher cellular uptake. Biochem Pharmacol., 2010, 80(7), 1021-1032.

[69] Li, W.; Chen, L.; Huang, Z.; Wu, X.; Zhang, Y.; Hu, Q.; Wang, Y. The influence of cyclodextrin modification on cellular uptake and transfection efficiency of polyplexes. Organic biomol. Chem., 2011, 9(22), 7799-7806.

[70] Buriez, O.; Heldt, J.M.; Labbé, E.; Vessières, A.; Jaouen, G.; Amatore, C. Reactivity and antiproliferative activity of ferrocenyltamoxifen adducts with cyclodextrins against hormone-independent breast-cancer cell lines. Chemistry., 2008, 14(27), 8195-8203.

[71] Dreassi, E.; Zizzari, A.T.; Mori, M.; Filippi, I.; Belfiore, A.; Naldini, A., et al. 2-Hydroxypropyl- $\beta$-cyclodextrin strongly improves water solubility and anti-proliferative activity of pyrazolo[3, 4d]pyrimidines Src-Abl dual inhibitors. Eur J Med Chem., 2010, 45(12), 5958-5964.

[72] Meinguet, C.; Masereel, B.; Wouters, J. Preparation and characterization of a new harmine-based antiproliferative compound in complex with cyclodextrin: Increasing solubility while maintaining biological activity. Eur J Pharm Sci., 2015, 77, $135-140$. 